\title{
Applying regulatory science in traditional chinese medicines for improving public safety and facilitating innovation in China: a scoping review and regulatory implications
}

\author{
Zuanji Liang, Yunfeng Lai, Meng Li, Junnan Shi, Chi leong Lei, Hao Hu and Carolina Oi Lam Ung* (1)
}

\begin{abstract}
Background: The National Medical Products Administration (NMPA) in China has set to advance the regulatory capacity of traditional Chinese medicines (TCMs) with the adoption of regulatory science (RS). However, the priority of actions at the interface of RS and TCMs were yet to be defined. This research aims to identify the priority areas and summarize core actions for advancing RS for traditional medicines in China.

Methods: A mixed approach of documentary analysis of government policies, regulations and official information about TCMs regulation in China, and a scoping review of literature using 4 databases (PubMed, ScienceDirect, Scopus and (NKI) on major concerns in TCMs regulation was employed.

Results: Ten priority areas in the development of TCM-related regulatory science in China have been identified, including: (1) modernizing the regulatory system with a holistic approach; (2) advancing the methodology for the quality control of TCMs; (3) fostering the control mechanism of TCMs manufacturing process; (4) improving clinical evaluation of TCMs and leveraging real world data; (5) re-evaluation of TCMs injection; (6) developing evaluation standards for classic TCMs formula; (7) harnessing diverse data to improve pharmacovigilance of TCMs; (8) evaluating the value of integrative medicine in clinical practice with scientific research; (9) advancing the regulatory capacity to encourage innovation in TCMs; and (10) advancing a vision of collaboration for RS development in TCMs.
\end{abstract}

Conclusions: RS for TCMs in China encompasses revolution of operational procedures, advancement in science and technology, and cross-disciplinary collaborations. Such experiences could be integrated in the communications among drug regulatory authorities to promote standardized and scientific regulation of traditional medicines.

Keywords: Regulatory Science, China, Traditional medicine, TCM, Drug Regulatory Authority, National Medical Products Administration

\section{Background}

Regulatory Science (RS) is a comparatively new discipline that has been adopted by drug regulatory authorities (DRAs) with the objectives to enhance the scientific

*Correspondence: carolinaung@um.edu.mo

State Key Laboratory of Quality Research in Chinese Medicine, Institute

of Chinese Medical Science, University of Macau, Macao, Taipa, China rationale supporting their benefit/risk analysis and regulatory decisions based on best available science [1]. The Food and Drug Administration (FDA) in the US considers RS as a science of developing new tools, standards, and approaches to assess the safety, efficacy, quality, and performance of all FDA-regulated products [2]. Similarly, the European Medicines Agency (EMA) in the European Union defines RS as a range of scientific disciplines that

(c) The Author(s) 2021. This article is licensed under a Creative Commons Attribution 4.0 International License, which permits use, sharing, adaptation, distribution and reproduction in any medium or format, as long as you give appropriate credit to the original author(s) and the source, provide a link to the Creative Commons licence, and indicate if changes were made. The images or other third party material in this article are included in the article's Creative Commons licence, unless indicated otherwise in a credit line to the material. If material is not included in the article's Creative Commons licence and your intended use is not permitted by statutory regulation or exceeds the permitted use, you will need to obtain permission directly from the copyright holder. To view a copy of this licence, visit http://creativeco mmons.org/licenses/by/4.0/. The Creative Commons Public Domain Dedication waiver (http://creativecommons.org/publicdomain/ zero/1.0/) applies to the data made available in this article, unless otherwise stated in a credit line to the data. 
are applied to the quality, safety and efficacy assessment of medicinal products and emphasizes on the entirety of the product lifecycle [3]. RS to the Pharmaceuticals and Medical Devices Agency (PMDA) in Japan plays an important role in optimally adapting technology achievements to social and human needs by making precise prediction, evaluation and judgment based on the best evidence available [4]. RS has been increasingly considered as the scientific discipline underpinning the scientific and technical foundations of drug regulatory authorities (DRAs) across the countries.

In China, the National Medical Products Administration (NMPA) highly recognized the values of RS to form the basis of regulatory activities. In May 2019, the NMPA launched the Action Plan of Regulatory Science which is the first official initiative that synchronizes the global trend of RS development [5]. To enhance the regulatory capacity, it is clearly stated in the Action Plan that the regulatory agency is committed to developing new regulatory tools, standards and methods in responses to both experienced and foreseeable challenges from the practical situation. The overall goal is for the regulatory decision-making process at the NMPA to become more scientific, forward-looking and adaptable in the new era of regulatory paradigm. According to the Deputy Director of NMPA, "By developing and adopting regulatory science, the drug regulation system in China will adhere to the five main attributes of innovation, quality, efficiency, system, and capability [6]."

The Action Plan of RS listed out the first batch of 9 key RS development areas in China which broadly covered a wide range of regulated products (such as pharmaceutical products, medical device, and drug-device combination products) and technology (such as cell and gene therapy, nanotechnology, and real world evidence) [5]. One of the 9 key RS areas was specifically dedicated to the evaluation of the safety of traditional Chinese medicines (TCMs) informed with the clinical practice of Traditional Chinese Medicine (TCM) theory. TCM refers to medicinal substances and preparations used under the guidance of TCM theory, which contains herbs, minerals and animal substances. This has successfully marked the unique application of RS on traditional medicine calling for immediate actions to accelerate advancement. While the RS plan in China has emphasized the importance of TCMs, further specifications about the areas of concerns have not been systematically analyzed. This paper aims to present a snapshot about applying RS in the regulation of TCMs in China and to propose actions essential to the support such development in the best interest of public health and industry growth. It is envisioned that the experiences of developing RS in TCMs in China may also become a valuable RS development blueprint for other
DRAs which strive to ensure the quality use of traditional and complementary medicines.

\section{Methods}

A mixed approach involving documentary analysis of government policies, regulations and official information about TCMs and RS in China, as well as relevant a scoping review of literature was employed in this study since Jan 01, 2000 (3 years before the introduction of the concept about developing scientific approaches to improve the health of the population in China [7]) to Jul 31,2020 . The publicly government documents were identified from the official websites: The State Council, The People's Republic of China (http://english.www.gov.cn/), The National Medical Products Administration (http:// english.nmpa.gov.cn/), and The National Administration of Traditional Chinese Medicine (http://www.satcm.gov. $\mathrm{cn} /$ ), The Center for Drug Evaluation of NMPA (http:// www.cde.org.cn/), and The Center for Information of NMPA (http://www.sfdaic.org.cn). The government collected documents were classified and further analyzed according to the registration category, market access requirements and post-marketing regulation of TCM.

On the other hand, literature published since 2000 was searched from 3 English electronic databases (including PubMed, ScienceDirect, Scopus) and 1 Chinese electronic database (Chinese National Knowledge Infrastructure, CNKI) using the search terms: ("regulatory science" OR "government regulation" OR "Government Regulation" $[\mathrm{MeSH}]$ ) AND ("traditional Chinese medicine" "TCM" OR "traditional medicine" " OR "integrative Medicine" OR "Medicine, Traditional" [MeSH] OR "Medicine, Chinese Traditional" [MeSH] OR "Integrative Medicine" $[\mathrm{MeSH}])$ AND "China". Publications which refer to the study, review, comment of TCMs regulation were selected independently by 2 researchers and included in this study for further data analysis upon careful assessment and agreement by the research team. Studies which were about clinical trial, meta-analysis, or randomized controlled trials of TCMs were excluded.

\section{Results}

\section{Ten priority areas of RS development in TCMs}

The core responsibility for the NMPA is to ensure the safety, effectiveness and quality control data of TCMs (and all the pharmaceutical products) approved for marketing. For achieving such goals, strengthening the regulatory systems through developing RS is considered a core action $[8,9]$. At present, the TCMs regulated by NMPA are divided into medicinal materials, decoction pieces and finished medicines. Considering the "complexity" and "variability" of the processes of "from planting and production to final clinical application", and 
"from medicinal materials and decoction pieces to finished products", the regulatory requirements for TCMs is distinctively different from that for chemical drugs [10]. Advancing RS by the NMPA will have important implications for the regulatory capacity to overcome challenges in the decision-making process about TCMs. In the following, 10 priorities areas in TCMs regulation worth the leading effort of RS development by the NMPA are proposed.

\section{Priority Area 1: modernizing the regulatory system with a holistic approach}

The regulation of TCMs is a prolonged and highly complex process starting from the planting field to bedside and beyond. Each domain of the process requires different yet standardized and continuous skillset at technical and operational levels. However, the current drug regulatory system in China is characterized by a tiered approach involving the central and the local governance over various phases of regulatory process. At different stages of the drug lifecycle, the regulation process is generally carried out by different offices of national and provincial drug regulatory departments [11]. In other words, the process of drug regulation is divided into several operation blocks such as registration, production, circulation and adverse reaction monitoring [11, 12]. Besides, under the phased mode of the regulatory process, each regulatory department has its own scope of regulation, and an apparent lack of effective communication between different regulatory departments, as well as between each regulatory authority and the applicants [12]. This may inevitably affect the availability and accessibility of information necessary for regulatory decision-making, and loopholes in the overall regulatory paradigm may thus result, affecting the rigor of the regulatory mechanism [13]. At the same time, the efficiency in the use of regulatory resources may also be jeopardized.

From the experiences of DRAs, a shift towards a holistic approach that integrates product-base system-base approaches is recommended to ensure drug safety and risk management throughout the product lifecycle. As such, the operation blocks at each stage of product lifecycle can be connected with data flow and information transfer to complete the regulatory chain that allows a helicopter view of planning, monitoring and control achieving dynamic management. In the newly revised Drug Administration Law and Provisions for Drug Registration, the concept of marketing authorization holder (MAH) has been officially adopted. On one hand, it allows domestic research institutions, drug manufacturers, and individuals to hold licenses to market drug products without holding a manufacturing license for a facility. On the other hand, more importantly, it sets forth a concrete, consolidated list of MAH responsibilities. Together with stronger pharmacovigilance and post-market surveillance system in place, MAH is now required to take responsibility of the safety, efficacy, and quality of their drugs during the entire "lifecycle," including nonclinical research, clinical trials, manufacture, distribution, and post-marketing surveillance. This echoes the regulatory requirements set forth by the DRAs in the US, EU and Japan [14]. In addition, NMPA has also adopted the International Council for Harmonization of Technical Requirements for Pharmaceuticals for Human Use (ICH) Q12 "Technical and regulatory considerations for pharmaceutical product lifecycle management" that emphasizes on the importance of data availability and stability to inform the regulatory decisions made throughout the product lifecycle $[15,16]$.

Stable and controllable quality of TCMs is the basis of stable quality and the curative effect of TCMs. For this, NMPA issued the Good Agricultural Practice (GAP) in 2002 [17] in order to help minimize the risks of germplasm confusion, as well as the overuse of pesticide and fertilizer in the growing of medicinal materials. On the other hand, WHO guidelines on good agricultural and collection practices (GACP) [18]" "for medicinal plants were published in 2003. Another area of concern regarding TCMs was the possible use of endangered animals. As early as 1987, the State Council of China issued the Regulations on the Protection and Management of Wild Medicinal Materials Resources [19] aiming to protect wildlife resources and discourage artificial breeding with legal forces.

In order to meet the requirements of traceability and monitoring of the quality of TCM products, the Opinions of the State Council on Accelerating the Construction of Traceability System for Important Products [20] was implemented followed by the Guiding Opinions on the Construction of Drug Information Traceability Information System [21], Guidelines for drug Traceability Information System Construction [22] and Encoding Requirements for Drug Traceability Code [23]. Collectively, these documents provide a framework of standard requirements for developing drug traceability system to ensure the traceability of a drug's entire lifecycle. Meanwhile, NMPA also launched the Action Plan for Accelerating the Smart Regulation of Drugs [24], which encourages the implementation of a big data regulatory infrastructure based on the drug traceability system to further improve the drug surveillance system.

The core responsibility of developing RS here is to advance and improve the existing regulatory systems and infrastructure to reinforce the monitoring and traceability of TCMs across the entire product lifecycle from raw materials to bedside [25]. Actions are needed to 
strengthen the inter-departmental regulatory coordination mechanism and encourage internal and external communication and collaboration to engage diverse key stakeholders such as the Centers for Disease Control, MAH, manufacturer, distributors, users, and other technical institutions. Information technology and other innovations are needed to lead the development of scientific infrastructure for the regulatory agencies at different levels to advance the data collection and sharing, and surveillance of TCMs throughout their lifecycle.

\section{Priority Area 2: advancing the methodology for the quality control of TCMs}

At present, the scientific and systematic research on medicinal materials, decoction pieces and extracts are still ongoing. In the Chinese Pharmacopoeia (Ch.P) 2015 , out of the 655 enlisted medicinal materials, decoction pieces and extracts, 210 lacked the qualitative and quantitative analysis of the major constituents while the systematic research for more than $80 \%$ of TCMs are yet to complete [26]. Even for those monographs and standards already developed (which already specify definitions, characters, identification, tests, assays, storage information, and more), such standards may not be specific enough and sometimes fall short to differentiate highly similar herbal species. Considering the various levels of complexity in the combination of the ingredients and the multiple chemical constituents of each ingredient, as well as the lack of standardization in the formulation when used in practical setting, the quality and standard data currently available is not sufficient to support the formulation of a comprehensive and effective system of quality standards for TCMs [26].

The efficacy and safety of TCMs are highly associated with the quality. However, unlike chemical synthetic drugs, TCMs is a complex chemical system and the quality is attributed by the chemical components of many structurally diverse compounds. Not surprisingly, the development of quality control and standards for most herbal materials, processed herbal preparation, and the final product of TCMs are highly challenging [10]. Moreover, the characteristics of synergistic reactions among different components, action channels and effect targets are difficult to be elucidated by the study model of "single component and single target" in modern medicine. Therefore, a scientific and effective system for evaluating the efficacy and safety of TCMs should be prioritized on the quest.

Great progress has been made in recent years to clarify the substance base and the mechanisms of actions for some TCMs. For the development of quality standards, biological assay has been recommended to better ensure the quality of TCM sources, authentication of species and preparations, stability of intermediate extracts, and the consistency of preparations [27]. The Guiding Principles for Bioassay of TCMs [28] has been adopted and published in General Principles of Ch.P for quality control of TCM. Similarly, the Botanical Drug Development Guidance for Industry also clearly indicates that biological assay is an important content of new drug registration review of botanicals in the US [29]. In addition, the concept of quality markers [30, 31], biological activity and biological response [32], as well as intelligent quality management [33] have also been suggested for the evaluation of TCMs quality [34-37]. Meanwhile, modern analytical technologies such as mass spectrum and chemometrics hold promising potentials to continuously contribute to the identification of potential quality markers of the herbs [38, 39], and other TCMs preparations $[40,41]$.

With the development of RS, it is urgent to develop new technologies and methods for advancing the approaches in the quality standards, control and evaluation, as well as the traceability system that addresses the unique features of herbs and TCMs across the entire lifecycle. Recently, the National Natural Science Foundation of China listed the quality markers of TCMs as a key project in 2018. Academic experts have already conducted discussions about the applicability of the quality markers of TCMs and published hundreds of related articles. Some key universities and large-scale Chinese medicine enterprises in China have already carried out relevant scientific research to be integrated in the drug development process. Developing RS should benefit not only the development of new methods and technologies, but also the coordination of research patterns and research efforts to justify the rationale for any developments in TCMs quality control and assessment system in a more efficient manner.

\section{Priority Area 3: fostering the control mechanism of TCMs manufacturing process}

Currently, the quality control through sample testing of raw materials, intermediate products and final products are mostly conducted manually in a detached manner. As such, the test results may not be able to fully and comprehensively reflect the quality of TCMs, and the approach is neither conducive in detecting changes in the production process and nor sensitive in identifying problems in time [42]. This is especially the case for traditional pharmaceutical process of TCMs that features the following: (1) low level of automation that affects the consistency of the operation and thus the product quality; (2) poor information integration capability that supports an automatic control system; (3) insufficient openness of the system that affects the interoperability and interchangeability of 
the bottom control appliances; and (4) poor maintainability and unreliable dependability of the appliance [43]. An operational procedure that strictly and accurately control the various control points (pretreatment, extraction, separation, concentration, dehydration and formulation) of the TCMs pharmaceutical process leading to a technological process control will have a direct impact on quality and effect of products.

In the US, the FDA launched the process analysis technology (PAT) program in 2002 and issued the Guidance for Industry about PAT in 2004 [44]. Gradually, PAT became the reform direction and research focus in the field of quality control in pharmaceutical industry. In 2016, the Ministry of Industry and Information Technology in China launched the "Planning Guide for the Development of Pharmaceutical Industry" which proposed the use of PAT to optimize pharmaceutical process and quality control, and realize the technical convergence and product quality consistency of pharmaceutical products [45]. As a powerful PAT tool, near-infrared spectroscopy has been adopted in real-time monitoring of TCMs technological processes [46]. Similarly, the NMPA also encourages the use of Quality by Design $(\mathrm{QbD})$ as a means to continuously improve the consistency of the product quality and to monitor for contamination or other production failures during the manufacturing process. The concept of $\mathrm{QbD}$ has evolved with the issuance of ICH Q8 (R2) (Pharmaceutical Development), ICH Q9 (Quality Risk Management), and ICH Q10 (Pharmaceutical Quality System) [47]. For drug regulators, analysis of QbD information would help acquire a better understanding about the possible variations, grasp the inevitable differences between batches, and ensure that the review conclusions are as scientific as possible.

The use of novel science and technologies, such as analytical technology to monitor and control processes or statistical methods to discover any variations in manufacturing process or product quality, is vital in light of the complexity of manufacturing process and innovation of TCMs. To this end, it is important for the NMPA to reinforce the research capacity guided by RS to assess how to develop and best use new technologies to the assurance of product safety, efficacy, and quality, and to do so in collaboration with industry and academia when developing regulatory policies corresponding to these innovations.

\section{Priority Area 4: improving clinical evaluation of TCMs and leveraging real world data}

The mainstream of medical knowledge and practice in the world is evidence-based medicine which recognizes the values of scientific evidence, and the efficacy and safety of any clinical interventions is primarily determined by clinical evidence. Undoubtedly, it is an important task to leverage evidence-based clinical study and evaluation of TCMs [48]. Nevertheless, it remains highly challenging to integrate the TCMs characteristics into the design methods for various reasons. Firstly, the design quality of randomized controlled trials (RCTs) is often weak at the randomization and allocation method and the evaluation of efficacy outcome in the blind trials. Secondly, while the diagnosis based on the TCM theory is an important factor in identifying eligible research objects in clinical research of TCMs, there is a lack of internationally recognized diagnostic criteria. Thirdly, there is a lack of standardized and quantitative evaluation indicators of curative effects such as "treating the root cause" or "strengthening the foundation" affecting the evaluation of clinical efficacy of TCMs. An additional challenge in TCMs research is the lack of standardization in the products, which is further complicated by the features of multiple active components found in numerous chemical compounds commonly seen in TCMs.

Evidence-based clinical practice guidelines of TCM and modified research models of the randomized controlled trial (RCT) have seen much progress in recent years. For instance, $\mathrm{N}$ of 1 trial, pragmatic trials, add-on design, expertise-based trials have been used for assessing clinical effect of TCM interventions including TCMs and other TCM practice [49]. Explanatory RCT has been used to test the efficacy in a research setting using highly selected study subjects and under highly controlled conditions [50]. Such design optimally balances out the effect of any actual or potential confounding factors when evaluating the efficacy of TCMs in comparison to placebo or active drugs. The pragmatic RCT design is more closely related to the "real world" clinical settings and is often used in the study of effectiveness comparison [51]. A series of one (N-of-one) trial is a special type of crossover trial which involves rounds of treatment crossovers within a single subject. This research design may be further repeated several times to confirm the results about the effectiveness of the TCMs in question [52]. To develop evidence about TCMs, the National Administration of Traditional Chinese Medicine established the Evidence-based Medicine Center of TCM in collaboration with the Chinese Academy of Chinese Medical Sciences in 2019. Around the same period, the "Evidence-based Capacity Building Project of TCM" [53] was also launched to promote the capacity building of developing evidence base for TCMs at clinical research bases and treatment centers in 31 provinces in China.

Furthermore, with the advent of the big data era, evidence-based evaluation methods of TCMs need to be continuously developed and updated. In China, the importance of real world evidence was to fill the research gaps due to the limitations of traditional TCMs clinical 
trials and to address the needs for additional evidence to inform policy decisions [54]. NMPA recently published the "Guiding Principles of Real World Evidence Supporting Drug Research and development and Evaluation (Trial)" [55], which proposed innovative strategies of combining real world study with RCT as new paths of clinical research and development, and clinical effectiveness and safety evaluation, thus supporting drug regulatory decision-making. Collectively, it requires both modern clinical trial design and statistically sound methods to leverage clinical data and real world evidence for the evidence-based approach in the evaluation of TCMs treatment.

The value of RS here is to encourage encouraging innovation in clinical evaluation through collaborating with other stakeholders to develop and modernize clinical trial designs and statistical methods to encourage innovation in clinical evaluation of TCMs. At the same time, the NMPA should reinforce the regulations about the confidentiality, privacy protection, data sharing governance, and ethical approval of data collected from various sources. For this, the adoption of RS should see the outcome of a systematic approach in data collection and data quality control through the development of policy framework, regulatory documents and technical guidance. This should be a joint effort across institutions and stakeholders to foster mutual understanding and cooperation so that common goals and agendas can be shared among researchers, practitioners, and policymakers. As such, developing RS in this area will help ensure for the development and application of high-quality real world evidence to policy and regulatory decisions by the NMPA.

\section{Priority area 5: re-evaluation of TCM injection}

A TCM injection is a sterile preparation that may contain one or more purified extract of herbal materials formulated as a solution, emulsion, powder, or concentrated solution for injection into human body [56]. They are a unique type of TCMs preparation that has been widely used in clinical practice in China and remain the most popular dosage forms of TCMs due to their remarkable effects in certain diseases $[57,58]$ accounting for one third of all TCMs sales in hospitals [59]. However, there are continuous concerns over the safety of the TCM injections in light of the significant number of adverse drug reaction (ADR) reports [60-62]. Statistics show that ADR reports related to TCM injections account for $>50 \%$ of total ADR reports related to TCMs [63] resulting in a series of public warnings and other regulatory actions by the NMPA since 2006 [64].

Safety concerns over TCM injections include allergic reactions to any of the components or may be related to the insufficient quality control of the preparations which may be attributed to insufficient basic research and poor controllability of quality standards. According to the study by Li et al. [65], among the 134 of TCM injections manufactured by 224 manufacturers approved for sale by the NMPA in 2017, only 5 of them had their monographs published in the Ch.P (2015). The quality standards of the remaining 129 TCM injections (92.3\%) were documented in other national guidelines which set a comparatively lower benchmark of quality or consistency and may not undergo regular review and update as the monographs in Ch.P. The substandard requirements for the quality control of TCM injections have profound implications for the effective control of product quality [63]. This is especially the case for the TCM injections which were approved for sale many years ago and were thus exempted from the regulatory requirements about the safety and efficacy of the current standards.

There is an urgent need for post-marketing re-evaluation of TCM injections by methodological and rigorous testing that emphasizes on quality controllability and risk evaluation and management [66, 67]. In 2008, the Ministry of Health and NMPA and the National Administration of Traditional Chinese Medicine jointly issued the "Basic Principles for Clinical Use for TCM Injections" [68]. In 2009, the NMPA also issued the Work Plan for Re-evaluation of the Safety of TCM Injections [69] which called for comprehensive actions in risk investigation in production and quality control, risk-benefit evaluation across batches, and improvement of product quality standards. Seven guidance documents were subsequently published for public reflection in 2010 on safety evaluation of TCM injections in non-clinical research, clinical research, production process, quality controllability, risk control capability evaluation, risk benefit evaluation and risk management plan [70]. In 2015, "Opinions on Deepening the Reform of Review and Approval System and Encouraging the Innovation of Pharmaceuticals and Medical Devices" [71] re-emphasized the re-evaluation of pharmaceutical injections.

To this end, the development of RS should focus on developing a platform for safety evaluation that is compatible with TCM toxicity attributes to effectively address specific TCM toxicities and safety concerns [72, 73]. Network pharmacology which considers multi-target strategies over single-target approaches may offer an alternative and modernized way to investigate the ADR and toxicity of drugs $[74,75]$. The application of drug toxicology genomics and/or metabolomics at the earlystage of TCMs toxicity investigation should be explored [76-78]. Other techniques such as in-vitro multiparameter cell-based imaging method that featured high throughput may also be used as an alternative to animal testing to develop a mechanistic understanding of TCMs 
ADR. The post-marketing clinical research also provides important information needed for the re-evaluation of TCM injections. Using data from the pre-existing hospital information systems, re-evaluation studies of TCM injections about the post-marketing safety can be carried out using prospective nested case-control and prescription sequence analysis designs [79-81]. Other cuttingedge technologies such as fast screening methods based on drug-metabolizing enzymes and receptor pathways, computational toxicology, and molecular toxicology may offer a new system of TCMs safety evaluation techniques $[82,83]$.

\section{Priority Area 6: developing evaluation standards for classic TCM formula}

Ever since the National Administration of Traditional Chinese Medicine published the list of the first batch of classic TCM formula (CTCMF) in 2018 [84], CTCMF has become one of the most popular topics in the drug regulation sector in China. CTCMF refers to TCMs prescriptions passed down from the clinical practice of famous doctors in past dynasties which had been documented in ancient TCM textbooks, are still widely used, and have definite and distinctive curative effects which is based on experience of traditional use not necessarily contemporary RCTs. Under the assumption that the safety and efficacy of CTCMF have been verified through clinical practice for hundreds or thousands of years, the TCM Law [85] stipulates that, for drug registration purposes, the application will only need to include nonclinical safety data for the preparations of CTCMF. To further specify the registration requirements, the NMPA published three technical documents [86, 87], such as Administrative Provisions on Simplified Registration and Approval of CTCMF (Draft for Soliciting Opinions), to clearly define the evidence requirements for human use experience and to introduce the relevance of real world study as a source of human use experience [88].

Real world study is an important research method to establish high-quality clinical evidence of TCM intervention, which can embody the connotation of TCM to the maximum extent [89]. However, it remains a great challenge for the simplified application of CTCMF to determine: (1) the authenticity of the origins and sources of the raw herbal materials; (2) the quality standards and the substance benchmark of CTCMF and CTCMF preparations; (3) the basic requirements and principles for the comparative study of CTCMF preparations (standard decoction and new preparations); (4) the standard processing method and the right dosage range of CTCMF preparations; (5) the quality traceability system from medicinal materials to preparations that embodies the whole process quality control concept [90].
Multiple issues to be resolved through adopting RS may include: (1) development of quality markers of CTCMF to ensure quality stability and consistency; in the genuineness of medicinal materials and product industrialization; (2) determination of the genuineness of medicinal materials that specifies the origin, habitat, harvesting time, storage and transportation process, processing, resource balance, production scale of the raw herbs; (3) standardization of the preparation and manufacturing process from substance basis and standard decoction to industrial preparation; (4) information transferability and traceability across the product lifecycle incorporated with modern process control theory and norms (such as good engineering practice, GEP); (5) application of Good Agriculture Practice (GAP) to ensure quality traceability system of medicinal materials which may involve artificial cultivation and breeding [90].

\section{Priority Area 7: harnessing diverse data to improve pharmacovigilance of TCMs}

Effective pharmacovigilance is a key to the development of guidelines which ensures safe, effective use of TCMs. According to the definition of World Health Organization (WHO), Pharmacovigilance (PV) refers to the science and activities related to the detection, evaluation, understanding and prevention of adverse reactions or any other drug-related problems [91]. Adverse drug events (ADE), including adverse drug reactions (ADRs), drug quality problems, and drug interactions, will have a great impact on patients' health and significantly increase their medical costs [92-94]. An efficient PV system can not only monitor, evaluate and prevent adverse reactions or other related medical events but also be a key step to improve the drug regulatory system, clinical practice and public health plan [95].

Nevertheless, China's PV system is still developing as the current ADRs monitoring and reporting system fall short to fully support the regulation of TCMs across the product lifecycle. According to the experiences of DRAs, the utilization of healthcare database has gradually increased, especially in Europe, the US and Asia in recent years. These medical databases have been widely used to support drug discovery, comparative efficacy and safety evaluation of marketed drugs [96-99]. The US FDA and other medical regulatory agencies, pharmaceutical industry and drug safety researchers have been exploring the application of big data in PV [100]. Sentinel is a post-marketing monitoring system developed by the US FDA in 2008. As of 2018, there are medical data of more than 300 million people [101]. In order to promote cooperative research through the establishment of a health database network, the EMA has been coordinating European Network of Centres for Pharmacoepidemiology 
and Pharmacovigilance (ENCePP) in recent ten years, which includes about 200 public institutions and contract research organizations to participate in activities related to drug epidemiology and PV. Up to now, monitoring drug safety through big data has proved to be cost-effective and can quickly determine the internal links related to ADRs.

In the perspective of RS, although the development of real world evidence is at an early stage in China, a number of important government initiatives are already underway. One such program is the China Hospital PV System, which was started in 2015 by the National Centre for ADRs Monitoring at the NMPA. This nationwide program was designed to identify safety signals proactively and to assist the analysis of the association between drug exposure and ADE. This system combined with the current drug safety monitoring system helps to reinforce the PV capacity in the country. The system collects data in electronic medical records from 300 hospitals and from healthcare claims to generate real world drug safety evidence for integrative analysis using drug risk analytics tools to support regulatory decision-making [102]. China is also actively developing intelligent information technology for TCMs regulation. The Research Institute of TCM regulation has set up a "Big Data Research Center for TCM", relying on the "Database of National Center for ADRs Monitoring", uniting with the "Internet++" platform of TCMs nationwide and other eight centers of the institute, based on emerging technologies such as big data, blockchain and artificial intelligence, focusing on two key points: data marking in the whole lifecycle of TCM and timely identification of medication safety risks.

\section{Priority Area 8: evaluating the value of integrative medicine in clinical practice with scientific research}

Although the term integrative medicine (IM) has been used frequently in different healthcare settings, there is not a standard definition for it [103]. In China, IM refers to the integration of TCM modality and conventional medicine modality as TCM is usually practiced alongside with conventional medicine especially in hospital settings [104]. This is of particular importance for complex diseases which may not be addressed by one medical system alone. As with conventional medicine, IM emphasizes the importance of an evidence-base for effectiveness especially in the international perspective $[103,105]$. Although there are many successful examples of clinical practice integrated at therapeutic level, there are apparently a limited number of trials on IM and thus lack of evidence for IM which suggests that an IM approach may be beneficial for certain conditions [106-108].

To conduct trials on IM remains highly challenging due to the limitation of clinical trial designs [105]. Despite decades of research and integration, the fundamentals of TCM remain largely unchanged and its theories inexplicable to science [109-111]. The research evidence on the effectiveness of IM provided as a package of care is limited due to its complex nature and definition, lack of standardization and challenges in methodological design [112-114]. However, major breakthroughs have been reported recently. Since the COVID-19 outbreak in China, it is mandated that the use of IM must be strengthened to manage the pandemic at a national level. The scientific and technological emergency research project "Clinical Research on Prevention and Treatment of Pneumonia Infected by New Coronavirus by Combination of Chinese and Western Medicine" was officially launched [115]. As a result, real-world evidence for IM in the prevention and treatment of the infection has been mounting [116-119].

In order to improve the quality of IM research, supporting policies and initiatives are already in place. The Outline of the National Strategic Plan for the Development of TCM (2016-2030) mentioned that "using modern science and technology to promote the integration of Chinese and Western medicine, complementary advantages and collaborative innovation" is one of the key tasks [120]. Local governments, such as Guangdong Province, have issued 11 local standards, such as General Rules for the Revision of Clinical Practice Guidelines of TCM (Integrated Chinese and Western Medicine) [121], which provide methodological basis for the construction of clinical practice, comprehensive acquisition of evidence and evaluation. Methodology wise, pragmatic RCTs or observational studies with nested qualitative approaches (with both practitioners and patients) that mimic the complexity of health care provision in the 'real world' situations are worth investigating [103].

To combines two knowledge systems to become an alternative medical model, optimum evidence and optimum research methodology are essential [122]. Therefore, it is necessary to establish the curative effect and risk evaluation based on evidence-based medicine to support the integration of Chinese Medicine and conventional medicine. RS in IM may focus on developing reporting guidelines which provide guidance for researchers and reviewers to conduct and assess evidence about IM and to facilitate systematic reviews on effectiveness.

\section{Priority Area 9: advancing the regulatory capacity to encourage innovation in TCMs}

Chinese herbal medicines provide a wealth of potential source materials for drug discovery [123]. According to Deng, 3563 extracts and 5000 single compounds from 3000 therapeutic herbal medicines have been collected in China in 2007 [124]. A study in 2011 also revealed that in 
China, at least 130-140 new drugs, either single chemical entities extracted from herbal medicines or synthetically modified compounds, are currently in clinical use [123]. With the advantage of a long history of and a strong theory base for the clinical use, drug candidates have been successfully identified for drug discovery. For instance, goldthread (Coptis chinensis Franch.) which has been used as a TCMs to treat inflammatory symptoms and infectious conditions for more than 3000 years [125], was found to contain berberine. With modern science, it was found that berberine not only possesses antibiotic and anti-inflammatory properties [126, 127], but also exhibits beneficial effects for inflammatory bowel diseases, and modulates the activities of ERK, p38 MARK, and JNK to suppress $\mathrm{T} 17$ and $\mathrm{T} 1 \mathrm{~T}$ cell differentiation suggesting the potentials to becoming a therapeutic agent to treat type 1 diabetes mellitus [128]. Further studies also suggested that berberine may also be a promising treatment for cancer, depression, hypertension, and hypercholesterolemia [129].

Biochemical techniques and cutting-edge technologies have made available new approaches in drug discovery from Chinese herbal medicines from the predrug stage and the quasi drug stage into the full-drug stage [130]. The virtual mapping between databases of Chinese herbal ingredients and molecular targets of diseases represents a new approach of drug discovery [123]. To search for an active herbal ingredient or lead compound from herbal materials, new technologies such as supercritical carbon dioxide extraction technology, membrane separation technology, semi-bionic extraction method, molecular distillation technology, and enzyme method in extracting effective components of medicinal plants have been developed [131-134]. Systems pharmacology uses both experiments and computational analysis of regulatory networks to develop a new understanding of drug action across multiple scales of complexity ranging from molecular and cellular levels to tissue and organism levels [135]. Genomic, proteomic and metabolomic technologies, network analysis, and other high-throughput studies, as well as structural and biochemical studies, are also being used to conduct systems-level analysis of drug action and molecular targets [136, 137]. With continuous development, nanotechnology has been applied to the research and development of TCMs particularly for formulation optimization such as the controlled preparation of TCMs using specific microstructure and surface properties $[138,139]$.

These novel and increasingly complex approaches to drug discovery from Chinese herbal medicines present growing challenges to NMPA's readiness to evaluate new products. For this, RS must be one step ahead to equip the NMPA with the necessary tools and methods to reliably assess the safety and efficacy of products derived from these new scientific developments. New assessment tools and methodologies needed for the evaluation process of innovative products, and advancements in the expertise and infrastructure to evaluate new and emerging technologies can be facilitated through active collaboration with external partners. Reaching out to manufacturers and clinicians to identify areas of high public health need with few existing effective interventions might be of strategic advantages. Efforts should also be made to promote the development, standardization, and validation of new techniques for the assessment of quality, safety and effectiveness of new products across the sectors. Cross-disciplinary RS training and research to address scientific gaps and challenges posed by novel products are also needed.

\section{Priority Area 10: advancing a vision of collaboration for RS development in TCMs}

The challenge of drug innovation and development is not just a matter for drug regulatory authorities. It is necessary to study new science, new technology, new methods and new tools, to jointly promote and truly obtain the progress of applied science and technology, and to cooperate with all stakeholders. Established in 2013, China Society for Drug Regulation, which is headed by the NMPA, is a collaborative platform among government, academia and industry. At present, 17 professional committees have been set up to assist NMPA in the research about the theory, technology and method of drug regulation, and promote the innovation and development of drug RS in China.

Nevertheless, the technical support for RS development needs further strengthening. As such, NMPA has established multiple research bases and centers in universities for driving TCMs RS development such as Peking University and Tsinghua University [140-146], aiming to strengthen the construction of RS (Table 1). To consolidate the resources for RS development, NMPA has signed a series of cooperation agreements with universities and research institutes such as the Chinese Medicine Regulatory Scientific Research Cooperation Agreement with the Chinese Academy of Chinese Medical Sciences and Beijing University of Chinese Medicine to establish the Chinese Medicine RS Research Center (Research Institute) [142]. The overall goal is to resolve any technical challenges in TCMs evaluation and regulation through joint efforts in research on policies and mechanisms of TCMs innovation, as well as education and training scientific talents in TCMs regulation.

At the same time, NMPA has actively established different forms of strategic alliances with other countries, and strengthened cooperation and exchanges in its regulatory 
Table 1 Partnerships formed by NMPA for the development of RS

\begin{tabular}{|c|c|c|c|c|}
\hline & Time & Collaborators & Collaborating research base & Key research areas \\
\hline 1 & 2013/09 & $\begin{array}{l}\text { Tianjin Binhai Food and Drug Administra- } \\
\text { tion and Tianjin Institute of Pharmaceuti- } \\
\text { cal Research }\end{array}$ & $\begin{array}{l}\text { Tianjin Binhai Center for Food and Drug } \\
\text { Regulatory Science Research }\end{array}$ & Drug and food technology and policy \\
\hline 2 & 2015/08 & Peking University & $\begin{array}{l}\text { Peking University Asia Pacific Economic } \\
\text { Cooperation Regulatory Sciences Center } \\
\text { of Excellence }\end{array}$ & $\begin{array}{l}\text { Education and training, RS research and } \\
\text { innovation, international collaboration, } \\
\text { RS Information Technology and Policy }\end{array}$ \\
\hline 3 & $2016 / 12$ & $\begin{array}{l}\text { Fudan University and University of Copen- } \\
\text { hagen }\end{array}$ & Sino-Danish Regulatory Science Center & $\begin{array}{l}\text { Education and training, trainee exchange } \\
\text { and professionals training RS program }\end{array}$ \\
\hline 4 & 2018/04 & Tsinghua university & $\begin{array}{l}\text { Institute of Regulatory Science and Chinese } \\
\text { Medicine Research Institute }\end{array}$ & TCMs modernization and RS research \\
\hline 5 & 2019/04 & Sichuan University & $\begin{array}{l}\text { Medical Device Regulatory Science } \\
\text { Research Base }\end{array}$ & RS in medical device \\
\hline 6 & 2019/06 & Beijing University of Chinese Medicine & $\begin{array}{l}\text { Chinese Medicine Regulatory Science } \\
\text { Research Institute }\end{array}$ & $\mathrm{RS}$ in TCM \\
\hline 7 & 2019/06 & $\begin{array}{l}\text { China Academy of Chinese Medical Sci- } \\
\text { ences }\end{array}$ & $\begin{array}{l}\text { Chinese medicine Regulatory Science } \\
\text { Research Center }\end{array}$ & RS in TCM \\
\hline 8 & 2019/10 & Shenyang Pharmaceutical university & Drug Regulatory Science Research Base & $\begin{array}{l}\text { Course development, Education and train- } \\
\text { ing, Research in RS }\end{array}$ \\
\hline 9 & 2019/12 & Shandong university & Drug Regulatory Science Research Base & RS in pharmaceutical products \\
\hline 10 & 2019/12 & South China University of Technology & $\begin{array}{l}\text { Medical Device Regulatory Science } \\
\text { Research Base }\end{array}$ & RS in medical device \\
\hline 11 & 2020/04 & $\begin{array}{l}\text { Shanxi Medical products Administration } \\
\text { and Xi'an Jiaotong University }\end{array}$ & $\begin{array}{l}\text { Northwest Institute of Pharmaceutical } \\
\text { Regulatory Science }\end{array}$ & RS research, Training and Education \\
\hline
\end{tabular}

capacity and standard setting. Such efforts are important for the agency to grasp the most advanced scientific research achievements and regulatory experiences, carry out practical and effective transformation, and enhance regulatory capacity and standards. At present, China's international cooperation in drug regulation includes: $\mathrm{ICH}$, International Coalition of Medicines Regulatory Authorities (ICMRA), the Pharmaceutical Inspection Convention and Pharmaceutical Inspection Co-operation Scheme (PIC/S), the Global Coalition for Regulatory Science Research (GCRSR), International Medical Device Regulators Forum (IMDRF), WHO Good Regulatory Practices (GRP), etc.

\section{Discussion}

In this review, 10 priority areas in the development of TCM-related regulatory science in China have been identified, the major concerns reviewed, and core actions suggested for advancing RS for TCMs in China. As presented in Table 2, it has been proposed that NMPA when developing RS in TCMs has the prime duties to formulate scientific norms around the major concerns over the complexity and variability of the whole lifecycle of TCM, formulate scientific operational procedures (priority area 1), encourage the advancement and use of scientific means and technology (priority area 2,3,4,5,6,7,8,9), and develop inter-disciplinary collaborations (priority area 10) to address the goals in the RS initiative. The overall goal of the RS initiative in China and the proposed priority areas in TCMs share commonalities with the priorities set forth by the FDA [2] and EMA RS [3] in their respective RS action plan: improve the efficiency of the evaluation and approval process, deliver safe new products to patients faster, and strengthen the regulatory capacity to improve regulatory performance and thus patient outcomes.

Figure 1 summarizes an overview of the process of advancing RS for TCMs in this study. When the evaluation tools and concepts for medical innovation products fall short, NMPA should work proactively with manufacturers and the scientific community to identify and resolve critical development concerns and stimulate research through some activities, and then makes this information available to the public through core action to advancing the development of regulatory medical products. It is also important for the NMPA to constantly adjust and adopt new ideas and strategies in TCMs regulation to ensure quality and safety, and to promote continuous innovation in scientific research and development of TCM products, forging the collaborations with all stakeholders to tackle any technical concerns.

In light of the current challenges in the scientific development of TCMs, as Liu et al. proposed [147], a top-level design, and a top-down approach is needed for the sustainable development of RS in TCMs in China. Two principles unique to TCMs must be taken into consideration: 
Table 210 priority areas and core actions summarized for advancing RS in TCMs

\begin{tabular}{|c|c|c|c|}
\hline & Priority area & Major concerns & Core actions proposed \\
\hline 1 & $\begin{array}{l}\text { Modernizing the regulatory system with a } \\
\text { holistic approach }\end{array}$ & $\begin{array}{l}\text { (1) Existing regulatory mode } \\
\text { (2) Drug lifecycle management }\end{array}$ & $\begin{array}{l}\text { (1) Innovative regulation mode of drug lifecycle } \\
\text { (2) Establishment of drug information traceabil- } \\
\text { ity information system } \\
\text { (3) The Action Plan for Accelerating the Smart } \\
\text { Regulation of Drugs }\end{array}$ \\
\hline 2 & $\begin{array}{l}\text { Advancing the methodology for the quality } \\
\text { control of TCMs }\end{array}$ & $\begin{array}{l}\text { (1) Basic research of quality control } \\
\text { (2) Innovative quality control methods }\end{array}$ & $\begin{array}{l}\text { (1) Guiding Principles for Bioassay of TCM } \\
\text { (2) Identify and evaluate quality marker }\end{array}$ \\
\hline 3 & $\begin{array}{l}\text { Fostering the control mechanism of TCMs } \\
\text { manufacturing process }\end{array}$ & $\begin{array}{l}\text { (1) Possible variation of quality in product } \\
\text { manufacturing process } \\
\text { (2) Many control points in TCMs manufactur- } \\
\text { ing process }\end{array}$ & $\begin{array}{l}\text { (1) Develop a PAT tool such as near-infrared } \\
\text { spectroscopy } \\
\text { (2) Guidelines for QbD concept }\end{array}$ \\
\hline 4 & $\begin{array}{l}\text { Improving clinical evaluation of TCMs and } \\
\text { leveraging real world data }\end{array}$ & $\begin{array}{l}\text { The clinical evaluation of TCMs remains many } \\
\text { challenging }\end{array}$ & $\begin{array}{l}\text { (1) Establishment of TCMs evidence-based } \\
\text { Center } \\
\text { (2) Initiation of the Evidence-based Capacity } \\
\text { Building Project of TCM } \\
\text { (3) Guidelines for drug discovery and review } \\
\text { supported by real world evidence }\end{array}$ \\
\hline 5 & Re-evaluation of TCM injection & The risk of TCM injection safety & $\begin{array}{l}\text { (1) Initiation of re-evaluating TCM injection } \\
\text { program } \\
\text { (2) Guidelines for safety evaluation of TCM } \\
\text { injection }\end{array}$ \\
\hline 6 & $\begin{array}{l}\text { Developing evaluation standards for classic } \\
\text { TCM formula }\end{array}$ & $\begin{array}{l}\text { (1) Formulate methods and standards of } \\
\text { pharmacy and biology } \\
\text { (2) The development of quality markers }\end{array}$ & $\begin{array}{l}\text { Guidelines for application to the classic TCM for- } \\
\text { mula preparation and substance benchmark }\end{array}$ \\
\hline 7 & $\begin{array}{l}\text { Harnessing diverse data to improve pharma- } \\
\text { covigilance of TCMs }\end{array}$ & Monitoring of drug safety & $\begin{array}{l}\text { (1) Establishment of China Hospital Pharma- } \\
\text { covigilance System } \\
\text { (2) Establishment of Database of National Center } \\
\text { for ADRs Monitoring }\end{array}$ \\
\hline 8 & $\begin{array}{l}\text { Evaluating the value of integrative medicine in } \\
\text { clinical practice with scientific research }\end{array}$ & $\begin{array}{l}\text { Research evidence on the efficacy of integra- } \\
\text { tive medicine }\end{array}$ & $\begin{array}{l}\text { Developing guidelines and funding for clinical } \\
\text { practice of integrative medicine }\end{array}$ \\
\hline 9 & $\begin{array}{l}\text { Advancing the regulatory capacity to encour- } \\
\text { age innovation in TCMs }\end{array}$ & $\begin{array}{l}\text { (1) Technologies of drug discovery } \\
\text { (2) Demand for the assessment of new } \\
\text { products }\end{array}$ & $\begin{array}{l}\text { (1) Develop biochemical techniques and } \\
\text { cutting-edge technologies for drug discovery } \\
\text { (2) Equip new tools, methodologies and tech- } \\
\text { niques for the assessment of new products }\end{array}$ \\
\hline 10 & $\begin{array}{l}\text { Advancing a vision of collaboration for RS } \\
\text { development in TCMs }\end{array}$ & $\begin{array}{l}\text { The challenge of drug innovation devel- } \\
\text { opment requires to cooperate with all } \\
\text { stakeholders }\end{array}$ & $\begin{array}{l}\text { (1) Set up scientific research bases or centers } \\
\text { (2) International scientific collaboration }\end{array}$ \\
\hline
\end{tabular}

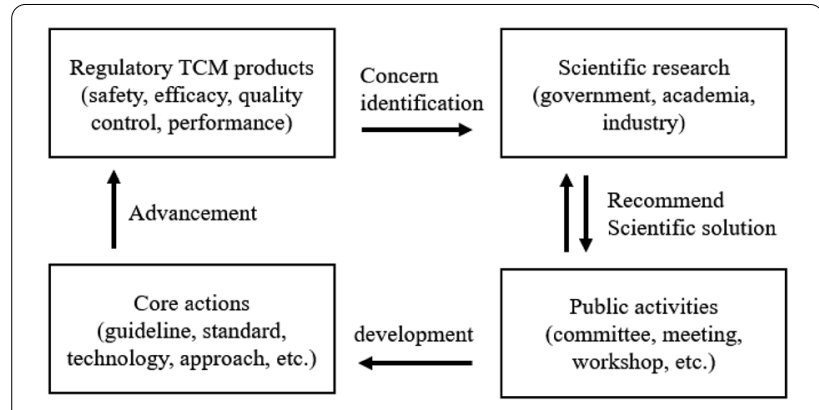

Fig. 1 The process of advancing RS for TCMs in China

(1) the development of TCMs should be considered as a "reverse transformation" of "clinical-trial-clinical" (clinical traditional use experience - clinical trial - clinical use); and (2) the research design of the clinical efficacy re-evaluation should be guided according to the principle of evidence-based medicine. In the process of implementing actions for RS development in TCMs, close attention should be paid to the development of policies, regulations, technical guidelines, technical methods and technical standards of TCMs research and development to effectively resolve the influencing factors affecting the quality, safety and efficacy of TCMs. It is also necessary to strengthen the cooperation among drug regulatory authorities, academia and industry, and improve the RS capacity of drug regulators so as to truly develop and utilize the scientific and technological advancements to promote the progress of RS in TCMs.

\section{Limitations}

There are some limitations in this paper. Firstly, considering that developing and adopting regulatory science especially in TCMs is still at its infancy, the breadth 
and depth of information available is limited. Therefore, instead of using systematic review suitable for analyzing exhaustive amount of information, the approach of scoping review was employed to capture key findings relevant to the research scope as much as possible. Secondly, the 10 priority areas in this paper are insufficient to fully identify and explain the possible variation of the current RS development in traditional medicines around the world. However, the paper findings may be used to inform the implementation strategy in the priority areas and summarize core actions to promote the development and address the current concerns of TCMs regulation in China and abroad. As outlined in the action plan, TCMs are considered one of the RS priorities calling for immediate actions to accelerate advancement.

\section{Conclusions}

RS for TCMs in China encompasses revolution of operational procedures, advancement in science and technology, and cross-boundary collaborations. Such experiences should be used to facilitate communications among drug regulatory authorities to promote standardized and scientific regulation of traditional medicines.

\begin{abstract}
Abbreviations
RS: Regulatory science; NMPA: The National Medical Products Administration; TCMs: Ttraditional Chinese medicines; TCM: Traditional Chinese Medicine; FDA: The Food and Drug Administration; EMA: European Medicines Agency; PMDA: Pharmaceuticals and Medical Devices Agency; DRAs: Drug regulatory authorities; MAH: Marketing authorization holder; QbD: Quality by Design; ICH: The International Conference on Harmonisation of Technical Requirements for Registration of Pharmaceuticals for Human Use; Ch.P: Chinese Pharmacopoeia; PAT: Process analysis technology; RCTs: Randomized controlled trials; RCT: Randomized controlled trial; CTCMF: Classic TCM formula; GEP: Good engineering practice; GAP: Good Agriculture Practice; PV: Pharmacovigilance; ADE: Adverse drug event; ADR: Adverse drug reaction; ADRs: Adverse drug reactions; ENCePP: European Network of Centres for Pharmacoepidemiology and Pharmacovigilance; IM: Integrative medicine; ICMRA: International Coalition of Medicines Regulatory Authorities; PIC/S: Pharmaceutical Inspection Convention and Pharmaceutical Inspection Co-operation Scheme; GCRSR: Global Coalition for Regulatory Science Research; GRP: Good Regulatory Practices; IMDRF: International Medical Device Regulators Forum.
\end{abstract}

\section{Acknowledgements}

We are also grateful to Chair Prof. Yi-Tao Wang for his technical guidance.

\section{Authors' contributions}

ZL and COLU conceived, designed the study and drafted the manuscript. YL, $\mathrm{ML}, \mathrm{JS}, \mathrm{CIL}$ and $\mathrm{HH}$ were major contributors in reviewing the manuscript. All authors read and approved the final manuscript. Based on the contributions, $\mathrm{ZL}$ is listed as the first author while COLU is the corresponding author. All authors read and approved the final manuscript.

\section{Funding}

This work was funded by the Science and Technology Development Fund, Macau SAR (No. 0013/2018/AFJ, sKL-QRCM(UM)-2020-2022) and the Research Fund of the University of Macau (MYRG2019-00143-ICMS).

\section{Availability of data and materials}

Data sharing is not applicable to this article as no datasets were generated or analyzed during the current study.
Ethics approval and consent to participate Not applicable.

\section{Consent for publication}

All of authors consent to publication of this work in Chinese Medicine.

\section{Conflict of Interest}

The authors declare that they have no competing interests.

Received: 25 August 2020 Accepted: 6 February 2021

Published online: 16 February 2021

\section{References}

1. Gispen-de Wied CC, Leufkens HGM. From molecule to market access: drug regulatory science as an upcoming discipline. Eur J Pharmacol. 2013;719(1-3):9-15.

2. US Food and Drug Administration. Advancing regulatory science at FDA: a strategic plan. 2011. https://www.fda.gov/media/81109/downl oad. Accessed 30 Jun 2020.

3. European Medicines Agency. Regulatory Science Strategy to 2025. 2019. https://www.ema.europa.eu/en/documents/regulatory-proce dural-guideline/ema-regulatory-science-2025-strategic-reflection _en.pdf. Accessed 30 Jun 2020.

4. Japanese Pharmaceuticals and Medical Devices Agency. Outline of regulatory science. https://www.pmda.go.jp/english/rs-sb-std/rs/0003. html. Accessed 30 Jun 2020.

5. The Center People's Government of the PRC. NMPA has initiated the "Action Plan on Regulatory Science in China. http://www.gov.cn/xinwe n/2019-05/02/content_5388253.htm. Accessed 30 Jun 2020 (Chinese).

6. National Medical Products Administration. Xu Jinghe attended the 2018 Global Summit on Regulatory Science. 2018. https://www.nmpa. gov.cn/yaowen/ypjgyw/20180926192601871.html. Accessed 30 Jun 2020 (Chinese).

7. The Central People's Government of the People's Republic of China. 2003: Scientific concept on development. http://www.gov.cn/ test/2009-10/10/content_1435066.htm. Accessed 30 Nov 2020 (Chinese).

8. National Medical Products Administration. Our Responsibilities. http:// english.nmpa.gov.cn/aboutNMPA.html. Accessed 30 Jun 2020.

9. Park YL, Canaway R. Integrating Traditional and Complementary Medicine with National Healthcare Systems for Universal Health Coverage in Asia and the Western Pacific. Health Systems Reform. 2019;5(1):24-31.

10. Chen YB, Tong XF, Ren J, et al. Current research trends in traditional Chinese medicine formula: a bibliometric review from 2000 to 2016. Evid Based Complement Alternat Med. 2019;2019:3961395.

11. Wang L, Chen W. Chen G. New drug research and development and regulatory management. In: Bai D, Chen K. Advanced pharmaceutical chemistry. Beijing: Chemical Industry Press; 2011. pp. 504-32.

12. Tang $M, X U$ J, Shi $L$, et al. Construction and countermeasures of administrative guidance system for local food and drug regulation. Chinese health resources. 2011;14(6):379. :- 83(Chinese.

13. Sun $X$. The construction and development of food and Drug regulation informatization, which sharpens the sharp instrument of regulation with modern information technology. China Food and Drug Administration. 2012;(03):12-5 (Chinese).

14. Zhu J, Shi L, Zhuansun Y, et al. Institutional analysis and enlightenment of marketing authorization holders in EU, USA and Japan. Shanghai Medical Pharmaceutical Journal. 2020;41(1):47-51. :(Chinese.

15. Center for Drug Evaluation of NMPA. Notice on Publicly Soliciting Opinions on Chinese Translation of ICH. "Q12: Technical and regulatory considerations for pharmaceutical product lifecycle management" and Annex. 2020. http://www.cde.org.cn/news.do?method=large Info\&id=1127bab280342dc0. Accessed 30 Jun 2020(Chinese).

16. Gong Q, Zhang X, Liu P, et al. Discussion of the product based supervision mode for the quality and efficacy consistency evaluation of generics. Shanghai Medical Pharmaceutical Journal. 2018;39(03):16."18 +23 (Chinese. . ;):\&\#8224.

17. The National Medical Products Administration. Good Agricultural Practice of Chinese herbal medicines. 2002. https://www.nmpa.gov. 
cn/yaopin/ypfgwj/ypfgbmgzh/20020417010101413.html. Accessed 30 Nov 2020 (Chinese).

18. World Health Organization. WHO guidelines on good agricultural and collection practices (GACP)ifor medicinal plants. World Health Organization. 2003. https://apps.who.int/iris/handle/10665/42783. Accessed 30 Nov 2020 (Chinese).

19. The State Council. Regulations on the Protection and Management of Wild Medicinal Materials Resources. https://www.nmpa.gov.cn/ xxgk/fgwj/flxzhfg/19871030010101420.html. Accessed 30 Nov 2020 (Chinese)

20. The State Council, The People's Republic of China. The Opinions of the State Council on Accelerating the Construction of Traceability System for Important Products. 2015. http://www.gov.cn/zhengce/conte nt/2016-01/12/content_10584.htm. Accessed 30 Jun 2020(Chinese).

21. National Medical Products of Administration. Guiding Opinions on the Construction of Drug Informationization Traceability System. 2018. http://www.nmpa.gov.cn/WS04/CL2196/331501.html. Accessed 30 Jun 2020 (Chinese).

22. National Medical Products of Administration. Guidelines for drug Traceability Information System Construction. 2019. https://www.nmpa.gov. cn/directory/web/nmpa/images/ufq80tKpxre84La9udzA7b7WMjAxOcTatdozMrrFuau45rigvP4xLnBkZg==.pdf. Accessed 30 Jun 2020.

23. National Medical Products of Administration. Encoding Requirements for Drug Traceability Code. 2019. https://www.nmpa.gov.cn/directory/ web/nmpa/images/ufa80tKpxre84La9udzA7b7WMjAxOcTatdozMrrFuau45rigvP4yLnBkZg==.pdf. Accessed 30 Jun 2020 (Chinese).

24. China Data Center for Food and Drug Administration of NMPA. Notice on issuing 'the Action Plan for Accelerating the regulation of Drug Wisdom.' https://www.nmpa.gov.cn/xxgk/fgwj/gzwj/gzwjzh/2019052417 5201644.html. Accessed 30 Jun 2020 (Chinese).

25. National Medical Products of Administration. Interpretation of drug traceability standards and specifications. 2020. https://www.nmpa.gov. cn/xxgk/zhcjd/tjzhc/20200312100501422.html. Accessed 30 Jun 2020 (Chinese).

26. Xiong L, Peng C. Study on Q-Maker of Leonurus japonicus and Penthorum chinense based on basic conditions of Q-Marker. Chinese Traditional Herbal Drugs. 2016;47(13):2212-20. (Chinese .

27. You Y, Liao FY, Huang LQ. Development of bioassay method in quality control of traditional Chinese medicine. China Journal of Chinese Materia Medica. 2018;43(3):452-6. :(Chinese

28. National Pharmacopoeia Committee. Guiding Principles for Bioassay of TCMs. Chinese Pharmacopoeia (Part 4). 2015ed: 9105-6(Chinese).

29. US Food and Drug Administration. Botanical Drug Development Guidance for Industry. 2016. https://www.fda.gov/media/93113/download. Accessed 30 Jun 2020 (Chinese).

30. Zhang T, Bai G, Han Y, Xu J, Gong S, Li Y, et al. The method of quality marker research and quality evaluation of traditional Chinese medicine based on drug properties and effect characteristics. Phytomedicine. 2018;44:204-11.

31. Li Y, Xie Y, He Y, Hou W, Liao M, Liu C. Quality markers of traditional Chinese medicine: concept, progress, and perspective. Engineering. 2019:5(5):888-94.

32. Wu X, Zhang H, Fan S, Zhang Y, Yang Z, Fan S, et al. Quality markers based on biological activity: a new strategy for the quality control of traditional Chinese medicine. Phytomedicine. 2018:44:103-8.

33. Bai G, Zhang T, Hou Y, Ding G, Jiang M, Luo G. From quality markers to data mining and intelligence assessment: a smart quality-evaluation strategy for traditional Chinese medicine based on quality markers. Phytomedicine. 2018:44:109-16.

34. Zhong Y, Zhu J, Yang Z, Shao Q, Fan X, Cheng Y. Q-marker based strategy for CMC research of Chinese medicine: a case study of Panax Notoginseng saponins. Phytomedicine. 2018;44:129-37.

35. Jiang Z, Yang J, Wang Y. Discrimination and identification of Q-markers based on 'spider-web' mode for quality control of traditional Chinese medicine. Phytomedicine. 2018;44:98-102.

36. Tang ZS, Liu YR, Lv Y, Duan JA, Chen SZ, Sun J, et al. Quality markers of animal medicinal materials: correlative analysis of musk reveals distinct metabolic changes induced by multiple factors. Phytomedicine. 2018:44:258-69.

37. Xiong Y, Hu Y, Li F, Chen L, Dong Q, Wang J, et al. Promotion of quality standard of Chinese herbal medicine by the integrated and efficacy-oriented quality marker of effect-constituent index. Phytomedicine. 2018;45:26-35.

38. Huang BM, Zha QL, Chen TB, Xiao SY, Xie Y, Luo P, et al. Discovery of markers for discriminating the age of cultivated ginseng by using UHPLC-QTOF/MS coupled with OPLS-DA. Phytomedicine. 2018;45:8-17.

39. Hou JJ, Cao CM, Xu YW, Yao S, Cai LY, Long HL, et al. Exploring lipid markers of the quality of coix seeds with different geographical origins using supercritical fluid chromatography mass spectrometry and chemometrics. Phytomedicine. 2018;45:1-7.

40. Ye J, Gao Y, Tian S, Su J, Zhang W. A novel and effective mode-switching triple quadrupole mass spectrometric approach for simultaneous quantification of fifteen ginsenosides in Panax ginseng. Phytomedicine. 2018:44:164-72.

41. Zhang H, Wu X, Xu J, Gong S, Han Y, Zhang T, et al. The comparative pharmacokinetic study of Yuanhu Zhitong prescription based on five quality markers. Phytomedicine. 2018;44:148-54.

42. Sheng P, Lo S, Yin L. Application of process analysis technology in pharmaceutical production process. Chin J Pharm Anal. 2018;38(05):748. :- 57(Chinese .

43. Ren LJ, et al. The Research and Detecting Techniques of Pharmaceutical Process Control System of Traditional Chinese Medicine. Technology for Education and Learning. 2012th ed. Vol. 136. Berlin: Springer Berlin Heidelberg; 2012. pp. 765-72.

44. US Food and Drug Administration. Guidance for industry: PAT, a framework for innovative pharmaceutical development, manufacturing and quality assurance. 2004. https://www.fda.gov/media/71012/ download. Accessed 30 Jun 2020 (Chinese).

45. Ministry of Industry and Information Technology of the People's Republic of China. Notice on issuing the Guidelines for the Development of Pharmaceutical Industry. http://www.miit.gov.cn/n1146295/ n1652858/n1652930/n3757016/c5343499/content.html. Accessed 30 Jun 2020 (Chinese).

46. Wang $X, X u B, X u X$, et al. Chinese medicine quality derives from design methods and application for-(II): Process Analytical Technology. World Chinese Medicine. 2018;13(03):527. :- 34(Chinese .

47. Center for Drug Evaluation of NMPA. Announcement on Four ICH Quality Guiding Principles Recommended for Application. 2020. https://www.nmpa.gov.cn/yaopin/ypggtg/ypqtgg/2020012117 1001817.html. Accessed 30 Jun 2020 (Chinese).

48. National Administration of Traditional Chinese Medicine. Zhang BL: the curative effect of traditional Chinese medicine can be evaluated by evidence-based method. 2016. http://www.satcm.gov.cn/xinxi fabu/gedidongtai/2018-03-24/4806.html. Accessed 30 Jun 2020 (Chinese).

49. Liu JP, Chen KJ. Methodology guideline for clinical studies investigating traditional Chinese medicine and integrative medicine: executive summary. Complement Ther Med. 2015;23(5):751.

50. Zwarenstein M, Treweek S, Gagnier JJ, et al. Improving the reporting of pragmatic trials: an extension of the CONSORT statement. BMJ. 2008;337:a2390.

51. Cao H, Chen W, Han M, Liu J. Designing a pragmatic randomized controlled trial: a commonly used method of comparative effectiveness research. Mod Chin Clin Med. 2015;22(2):32-5. (Chinese).

52. Guyatt GH, Keller JL, Jaeschke R, Rosenbloom D, Adachi JD, Newhouse MT. The n-of- 1 randomized controlled trial: clinical usefulness: our three-year experience. Ann Intern Med. 1990;112(4):293-9.

53. National Administration of Traditional Chinese Medicine. China Center for Evidence-based Medicine of Traditional Chinese Medicine plans to research on 9 kinds of diseases. 2019. http://www.satcm.gov cn/xinxifabu/gedidongtai/2019-09-11/10860.html. Accessed 30 Jun 2020 (Chinese).

54. Tian F, Xie YM. Real world study: a potential new approach to effectiveness evaluation of traditional Chinese medicine interventions. Zhong Xi Yi Jie He Xue Bao. 2010;8:301-6. :(Chinese .

55. National Medical Products of Administration. Guiding Principles of Drug Research and development and Evaluation Supported by Real World Evidence (Trial). http://www.nmpa.gov.cn/WS04/CL213 8/373175.html. Accessed 30 Jun 2020(Chinese). 
56. Wu R, Zhang B. Analysis on pharmacovigilance of traditional Chinese medicine injection. Chinese Journal of Rational Drug Use. 2011;8(3):48-51.

57. Tan LJ, Wang M, Zhu Y. Research progress of adverse reactions of traditional Chinese medicine injections. Chin Med Pharmaco Clinic. 2014;39(20):3889-98.

58. Liu Y, Xiao L, Liu Z, et al. Analysis on adverse reactions of traditional Chinese medicines injections through the ADRs information bulletin. Journal of Tianjin University of Traditional Chinese Medicine. 2018;37(2):92-5

59. Hu B. Innovation road of traditional Chinese Medicine injection. Sci Technol Guide. 2014;32(07):12 + 3 (Chinese).

60. Zhang L, Yan J, Liu X, et al. Pharmacovigilance practice and risk control of Traditional Chinese Medicine drugs in China: current status and future perspective. J Ethnopharmacol. 2012;140(3):519-25.

61. Ji KM, Li M, Chen JJ, et al. Anaphylaxis caused by Houttuynia Cordata injection, a herbal treatment in China. Allergy. 2009;64(5):816-17.

62. Chen L, Titch $T$, Luo Z, et al. Confirmation of a proarrhythmic risk underlying the clinical use of common Chinese herbal intravenous injections. J Ethnopharmacol. 2012;142(3):829-35.

63. Li H, Wang S, Yue Z, Ren X, Xia J. Traditional Chinese herbal injection: Current status and future perspectives. Fitoterapia. 2018;129:249-56.

64. Tan L, Li M, Lin Y. Safety concerns of traditional Chinese medicine injections used in Chinese children. Evid Based Complement Altern Med. 2019

65. Li H, Wang S, Yue Z, Ren X, Xia J. Traditional Chinese herbal injection: Current status and future perspectives. Fitoterapia. 2018;129:249-56.

66. Shi L, Xie Y, Liao X, Chai Y, Luo Y. Shenmai injection as an adjuvant treatment for chronic cor pulmonale heart failure: a systematic review and meta-analysis of randomized controlled trials. BMC Complement Altern Med. 2015:15:418.

67. Liu XT, Ren PW, Peng L, et al. Effectiveness and safety of ShenXiong glucose injection for acute ischemic stroke: a systematic review and GRADE approach. BMC Complement Altern Med. 2016;16:68.

68. National Medical Products Administration. Basic principles for clinical use for TCM injections. 2008. https://www.nmpa.gov.cn/xxgk/fgwj/ qita/20081224120001195.html. Accessed 30 Jun 2020 (Chinese).

69. National Medical Products Administration. Notice on re-evaluating the safety of traditional Chinese medicine injections.2009. https://www. nmpa.gov.cn/xxgk/fgwj/gzwj/gzwjyp/20090716152101457.html. Accessed 30 Jun 2020 (Chinese)

70. National Medical Products of Administration. Notice on re-evaluating the safety of traditional Chinese medicine injections in 2011. http:// www.nmpa.gov.cn/WS04/CL2196/323827.html. Accessed 30 Jun 2020 (Chinese).

71. The center People's government of the people's Republic of China. The General Office of the CPC Central Committee and the General Office of the State Council issued the Opinions on Deepening the Reform of the Review and Approval System and Encouraging the Innovation of Pharmaceutical Medical Devices.2015. http://www.gov.cn/zheng ce/2017-10/08/content_5230105.htm. Accessed 30 Jun 2020 (Chinese).

72. Lin M. Study in the risk factors of sensitization caused by Traditional Chinese Medicine and the sensitized components of Chinese medicine products [Dissertation]. Zhejiang University, Hangzhou, China, 2013.

73. Zhang B, Wu R. Thinking about the safety of traditional Chinese medicine injection. Clin Med J. 2006;6:14-8 (Chinese).

74. Hopkins AL. Network pharmacology: the next paradigm in drug discovery. Nat Chem Biol. 2008;4:682-90.

75. Li S, Zhang B. Traditional Chinese medicine network pharmacology: theory, methodology and application. Chin J Nat Med. 2013;11(2):110-20.

76. Han L, Wang Y, Yue G. Application of pregnane X receptor's regulation of induction of cytochrome P-450 CYP3A to incompatibility of traditional Chinese medicine and toxicity predetermination. Chin J Pharmacol Toxicol. 2015;6:967-72. (Chinese).

77. Hu C, Tang X, Li J, et al. Metabonomics study of aqueous extract of Fructus Psoraleae on serum of rats based on UPLC/QTOF-MS. Pharmacol Clin Chin Materia Medica. 2016;32(1):22-6. (Chinese).

78. Wang Y, Feng Q, He P, Zhu L, Chen G. Genomics approach of the natural product pharmacology for high impact diseases. Int J Genomics. 2018;2018:9468912.
79. Wang C, Shi Q, Ding F, et al. Re-evaluation of the postmarketing safety of Shuxuening injection based on real world and evidence-based evaluations. Drug Des Devel Ther. 2018;12:757-67.

80. Wang C, Shi QP, Ding F, et al. Re-evaluation of the post-marketing safety of Xuebijing injection based on real world and evidence-based evaluations. Biomed Pharmacother. 2019;109:1523-31.

81. Wang LX, Xie YM, Ai QH, Xu WF. Clinical safety studies based on 30 026 post-marketing cases of Shenqi Fuzheng injection by intensive hospital monitoring nested NCCS. China Journal of Chinese Materia Medica. 2015;40(24):4739-45. (Chinese).

82. Wen L, Wei F. Relationship among dosage, effect and toxicity of the ingredients in a Chinese herbal formula. Chin J Exp Traditi Med Formulae. 2009;15(5):84-7 (Chinese).

83. Ma ZC, Wang YG, Tan HL, et al. Interactions between drug metabolizing enzymes and traditional Chinese medicine. World Chin J Digestology. 2016;24(7):994-1001 (Chinese).

84. National Administration of Traditional Chinese Medicine. Notice of national administration of traditional Chinese medicine on Issuing the Catalogue of classic traditional Chinese medicine formulae (First Batch). 2018. http://kjs.satcm.gov.cn/zhengcewenjian/2018-0416/7107.html. Accessed 30 Jun 2020 (Chinese).

85. The State Council, the People's Republic of China. Law of the People's Republic of China on Traditional Chinese Medicine. 2016. http:// www.gov.cn/xinwen/2016-12/26/content_5152773.htm. Accessed 30 Jun 2020 (Chinese).

86. National Medical Products of Administration. Announcement on Issuing the Administrative Provisions on Simplified Registration Review and Approval of classic traditional Chinese medicine formula Preparations (No.27 of 2018). http://www.nmpa.gov.cn/WS04/CL209 3/228247.html. Accessed 30 Jun 2020 (Chinese).

87. National Medical Products of Administration. The Comprehensive Department of NMPA publicly solicited opinions on the requirements for the application document of the classic traditional Chinese medicine formula preparations and substance benchmark (draft for comments). http://www.nmpa.gov.cn/WS04/CL2101/335926.html. Accessed 30 Jun 2020 (Chinese).

88. National Medical Products Administration. Opinions on publicly soliciting six documents including the Special Provisions on the Registration and Administration of Traditional Chinese Medicine (Draft for Comment).2020. https://www.nmpa.gov.cn/xxgk/ggtg/qtggt g/20200430154501315.html. Accessed 30 Jun 2020 (Chinese).

89. Dai L, Ji G. Status and value of real world study on research and development of new Chinese medicine-interpreting framework for FDA's real world evidence program. Trad Chin Drug Res Clin Pharmacol. 2019;30(11):1403-8.

90. Liu C, Zhang T, Huang $L, X u H$. Developing regulation science for advancing inheritance and innovation of traditional Chinese medicine production. Drug Eval Res. 2019;10(42):1901-12 (Chinese).

91. World Health Organization. https://www.who.int/teams/regulation -prequalification/pharmacovigilance. Accessed 30 Jun 2020.

92. Harpaz R, Dumochel W, Shah NH. Big data and adverse drug reaction detection. Clin Pharmacol Ther. 2016;99(3):268-70.

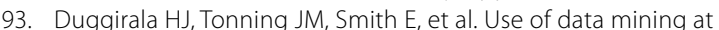
the Food and Drug Administration. J Am Med Inform Assoc. 2016;23(2):428-34.

94. Vilar S, Friedman C, Hripcsak G. Detection of drug-drug interactions through data mining studies using clinical sources, scientific literature and social media. Brief Bioinform. 2017;19(5):863-77.

95. World Health Organization. Pharmacovigilance: ensuring the safe use of medicines. World Health Organization. 2004. https://apps.who.int/ iris/handle/10665/68782.

96. Hripcsak G, Albers DJ. Next-generation phenotyping of electronic health records. J Am Med Inform Assoc. 2012;20(1):117-21.

97. Wagholikar KB, Sundararajan V, Deshpande AW. Modeling paradigms for medical diagnostic decision support: a survey and future directions. Journal of medical systems. 2012;36(5):3029-49.

98. Sullivan P, Goldmann D. The promise of comparative effectiveness research. JAMA. 2011;305(4):400-1.

99. Bate A, Juniper J, Lawton AM, et al. Designing and incorporating a real world data approach to international drug development and use: what the UK offers. Drug Discov Today. 2016;21(3):400-5. 
100. Moore TJ, Furberg CD. Electronic health data for post-market surveillance: a vision not realized. Drug Saf. 2015;38(7):601-10.

101. Ball R, Robb M, Anderson SA, et al. The FDA's sentinel initiative-a comprehensive approach to medical product surveillance. Clin Pharmacol Ther. 2016;99(3):265-8.

102. Sun X, Tan J, Tang L, Guo JJ, Li X. Real world evidence: experience and lessons from China. BMJ. 2018;361:k1580.

103. Hu XY, Lorenc A, Kemper K, et al. Defining integrative medicine in narrative and systematic reviews: a suggested checklist for reporting. European Journal of Integrative Medicine. 2015;7(1):76-84.

104. Robinson N, Liu J, di Sarsina PR, Haramati A. Educating for integration. Eur J Integr Med. 2014;6(1):1-4.

105. Appleyard I, Lundeberg T, Robinson N. Should systematic reviews assess the risk of bias from sham-placebo acupuncture control procedures? Eur J Integr Med. 2014;6(2):234-43.

106. Rehberg B. Evidence-based integrative pain medicine. Eur I Integr Med. 2010;2(3):109-13.

107. Yang $H$, Yang J, Wen Z, Zha Q, Nie G, Huang X, et al. Effect of combining therapy with traditional Chinese medicine-based psychotherapy and herbal medicines in women with menopausal syndrome: a randomized controlled clinical trial. Evid Based Complement Altern Med. 2012;2012:354145.

108. Wang L, Zhang M, Guo L, Qi J, Luo H, He H, et al. Clinical pathways based on integrative medicine in Chinese hospitals improve treatment outcomes for patients with acute myocardial infarction: a multicentre, nonrandomized historically controlled trial. Evid Based Complement Altern Med. 2012:2012:821641.

109. Chen KJ, Xu H. The integration of traditional Chinese medicine and Western medicine. European Rev. 2003;11:225-35.

110. Kaptchuk TJ. The web that has no weaver: understanding Chinese medicine. Illinois: Contemporary Books; 2000.

111. Liang MX. The predicaments and future of the search for the nature of disease in traditional Chinese medicine. Beijing: The People's Medical Publisher; 1998. p. 1-48 (Chinese).

112. Marcus DM, McCullough $L$. An evaluation of the evidence in "evidencebased" integrative medicine programs. Acad Med. 2009;84(9):1229-34.

113. Nahin R, Straus S. Research into complementary and alternative medicine: problems and potential. Brit Med J. 2001;322(7279):161-4.

114. Hu X, Chen N, Yang G, Chai Q, Trevelyn E, Lorenc A, et al. Integrated treatment for low back pain: a systematic review. Eur I Integr Med. 2013;5(6):572

115. Gao S, Ma Y, Yang F, et al. ZHANG Boli: Traditional Chinese medicine plays a role in the prevention and treatment on novel coronavirus pneumonia. Tianjin Journal of Traditional Chinese Medicine. 2020;37(02):121-4 (Chinese).

116. Xia L, Wu H, Liu P, et al. Analysis on clinical efficacy and liver injury of 100 cases of COVID-19 treated by integrated traditional Chinese and western medicine. Shanghai Journal of Traditional Chinese Medicine. 2020;54(07):23-8. (Chinese).

117. Gao C, Song C, Fu Y, Zhang J. The Curative effect on treating COVID-19 by integrated medicine: a systematic review. J Shaanxi Univ Chin Med. 2020;117-25 (Chinese).

118. Li Y, Zhang W. Evaluation on the clinical effect of traditional Chinese medicine and western medicine regimens on COVID-19. Guangming Journal of Chinese Medicine. 2020;35(09):1273-5. (Chinese).

119. Liu Q, Xia W, An C, et al. Refection on effects of integrated traditional Chinese and western medicine on coronavirus disease 2019(COVID-19). Journal of traditional Chinese medicine. 2020;61 (6):463-4. (Chinese).

120. The Center People's Government of the PRC. Notice of the State Council on issuing the Outline of the Strategic Plan for the Development of Traditional Chinese Medicine. (2016-2030). http://www.gov.cn/zheng ce/content/2016-02/26/content_5046678.htm. Accessed 30 Jun 2020 (Chinese).

121. Guangdong Administration for Market Regulation. The local standards of Guangdong Province approved the release of 11 local standards such as the General Principles for the Revision of Clinical Practice Guidelines for Traditional Chinese Medicine (Integrated Traditiona Chinese and Western Medicine). http://amr.gd.gov.cn/zwgk/tzgg/conte nt/post_2729375.html. Accessed 30 Jun 2020 (Chinese).
122. Chen S. Integrative medicine and its definition. In: Chen K, editor. Introduction of integrative medicine. China Press of Traditional Chinese Medicine. 2005.71-80 [chapter 3].

123. Pan SY, Chen SB, Dong HG, et al. New perspectives on Chinese herbal medicine (Zhong-Yao) research and development. Evidence-based Complementary and Alternative Medicine. 2011;403709.

124. Deng ZL. Application of new techniques in the innovative research of Chinese herbal medicine. Chinese Pharmaceutical. 2007;16:58-89. (Chinese).

125. Zhu XZ, Li XY, Liu J. Recent pharmacological studies on natural products in China. Eur J Pharmacol. 2004;500(1):221-30.

126. Kuo CL, Chi CW, Liu TY. The anti-inflammatory potential of berberine in vitro and in vivo. Cancer Lett. 2004;203(2):127-37.

127. Yan D, Jin C, Xiao XH, Dong XP. Antimicrobial properties of berberines alkaloids in Coptis chinensis Franch. by microcalorimetry. J Biochem Biophys Methods. 2008;70(6):845-49.

128. Cui GL, Xia Q, Zhang YB, et al. Berberine diferentially modulates the activities of ERK, p38 MARK, and JNK to suppress Th17 and Th1 T cell differentiation in type 1 diabetic mice. J Biol Chem. 2009;284(41):28420-9.

129. Vuddanda PR, Chakraborty S, Singh S. Berberine: a potential phytochemical with multispectrum therapeutic activities. Expert Opin Investig Drugs. 2010;19(10):1297-307.

130. Pan SY, Zhou SF, Gao SH, Yu ZL, et al. New perspectives on how to discover drugs from herbal medicines: CAM's outstanding contribution to modern therapeutics. Evid Based Complement Alternat Med.2013;2013:627375.

131. Li F, Zhang Z, Sun X, Wang W, Ma M. Optimization of extraction conditions for semi-bionic extraction of Guizhi Fuling pill decoction by uniform design. Journal of Chinese Materia Medica. 2010;35(16):2151-6. (Chinese).

132. He Z, Xia W. Microwave-assisted extraction of phenolics from Canarium album $L$. and identification of the main phenolic compound. Nat Prod Res. 2011;25(2):85-92.

133. Lesellier E. Supercritical fluid chromatography for bioanalysis: practical and theoretical considerations. Bioanalysis. 2011;3(2):125-31.

134. Guo CX, Wang SK. Applications of the art technology in separations of effective components of natural products. Chemistry Bioengineering. 2006;23(5):38-40. (Chinese).

135. Berger SI, lyengar R. Network analyses in systems pharmacology. Bioinformatics. 2009;25(19):2466-72.

136. Wang Y, Bolton E, Dracheva S, et al. An overview of the PubChem BioAssay resource. Nucleic Acids Res. 2009;38(1):D255-66.

137. Wang Y, Xiao J, Suzek TO, et al. PubChem: a public information system for analyzing bioactivities of small molecules. Nucleic Acids Res. 2009;37(2):W623-33.

138. Deng $X$, Ruan $X$, Hao H. Study on matrix sustained-release tablets of brucine solid lipid nanoparticles. Chinese Traditional Herbal Drugs. 2018:49(22):5298-304. (Chinese).

139. Gu Q, You B, Yang D, et al. Development of Tripterygium glycosides nano-carries based on "nanoemulsion-gels" and its pharmacodynamics. China Journal of Chinese Materia Medica. 2015;40(01):73-8 (Chinese).

140. Liu CX. Development of drug regulatory science in the world. Drug Evaluation Research. 2017;40(08):1029-43. (Chinese).

141. National Medical Products Administration. Sichuan University Medical Device Regulatory Science Research Institute became the first medical device regulatory science research base of the National Medical Products Administration. 2019. https://www.nmpa.gov.cn/yaowen/ypjgy w/20190426175501231.html. Accessed 30 Jun 2020 (Chinese).

142. National Medical Products Administration. NMPA signed a cooperation agreement with China Academy Chinese Medical Sciences and Beijing University of Chinese Medicine on regulation science of Traditional Chinese Medicine. 2019. https://www.nmpa.gov.cn/yaowen/ypjgy w/20190627215001205.html. Accessed 30 Jun 2020 (Chinese).

143. The Drug Regulatory Science Research Base of National Medical Products Administration settled in Shandong University. 2019. https:// www.view.sdu.edu.cn/info/1003/128483.htm. Accessed 30 Jun 2020 (Chinese).

144. Drug Regulatory Science Research Base of National Medical Products Administration settled in Shenyang Pharmaceutical University. 2019. 
https://www.syphu.edu.cn/info/1064/5126.htm. Accessed 30 Jun 2020 (Chinese).

145. National Medical Products Administration. The National Medical Products Administration approved South China University of Technology as the Medical Device Regulatory Science Research Base. 2019. https:// www.nmpa.gov.cn/directory/web/nmpa/yaowen/ypjgyw/2019122315 4501155.html. Accessed 30 Jun 2020 (Chinese).

146. Meng $H Q$, Yang F, Gao WL. Northwest medicine Regulatory Science Research Institute Unveiled. Xin Xi Bu. 2020; (13):90 (Chinese).
147. Liu CX. A review of development of drug regulatory science in past 10 years (2010-2020). Drug Evaluation Research. 2020;43(7):1197-206 (Chinese).

\section{Publisher's note}

Springer Nature remains neutral with regard to jurisdictional claims in published maps and institutional affiliations.
Ready to submit your research? Choose BMC and benefit from:

- fast, convenient online submission

- thorough peer review by experienced researchers in your field

- rapid publication on acceptance

- support for research data, including large and complex data types

- gold Open Access which fosters wider collaboration and increased citations

- maximum visibility for your research: over $100 \mathrm{M}$ website views per year

At BMC, research is always in progress.

Learn more biomedcentral.com/submissions 